\title{
Spatial-Temporal Analysis the Dynamics of Changes on the Foreign Exchange Market: an Empirical Estimates from Ukraine
}

\author{
Oleg Vasiurenko ${ }^{1}$, Vyacheslav Lyashenko ${ }^{2}$, Valeria Baranova ${ }^{3}$, Zhanna Deineko ${ }^{4}$ \\ *Corresponding Email: lyashenko.vyacheslav@gmail.com \\ ${ }^{1}$ Vice-Rector on Economics, PVNZ, Kyiv Institute of Business and Technology, \\ Ukraine \\ ${ }^{2}$ Department of Informatics, Kharkiv National University of RadioElectronics, \\ Ukraine \\ ${ }^{3}$ Department of Travel Business and Regional Studies, V.N. Karazin Kharkiv \\ National University, Ukraine \\ ${ }^{4}$ Department of Software Engineering, Kharkiv National University of \\ RadioElectronics, Ukraine
}

Received: October 24, 2020

Revised: October 31, 2020

Accepted: November 2, 2020

\begin{abstract}
The foreign exchange market plays an important role in the formation and development of financial markets. This market is of particular importance for emerging economies. To understand market trends (to understand and develop a strategy for its development), it is necessary to analyze historical data. It is also important to use different methods to carry out this analysis. Based on this, the paper analyzes the foreign exchange market in Ukraine for the period 2014-2018. For this analysis, the wavelet coherence methodology is used. This made it possible to assess the development of the foreign exchange market in Ukraine.
\end{abstract}

Keywords: Forex Market, Wavelet Coherence, Currency Pair, Currency Sale

\section{Introduction}

The stable development of the Ukrainian economy is largely determined by changes in the foreign exchange market (Kuzemin et al., 2005; Lyashenko, 2014). This is due to the fact that the Ukrainian economy is largely dependent on foreign exchange borrowing in foreign markets. In this case, the foreign exchange market determines the value of the national currency. The foreign exchange market also contributes to the transformation of financial resources with the aim of their optimal use for the needs of various business entities. Therefore, it is important to take into account the dynamics of changes in the foreign exchange market and use such information in a timely manner to make appropriate decisions.

Justification and adoption of appropriate management decisions is based on the use of various mathematical methods and approaches that are used in the study of financial data (Dobrovolskaya \& Lyashenko, 2013; Vasiurenko \& Lyashenko, 2020).

A special place among the methods and approaches to the analysis of financial data is occupied by methods that are based on the theory of wavelets (Vasiurenko \& Lyashenko, 2020; Aloui et al., 2018). This is due to the fact that such methods allow you to identify and analyze hidden trends in the dynamics of data. It is this methodology that is used in this study. 
The main objective of this study is to analyze the dynamics of changes in the foreign exchange market using the theory of wavelets. As an example, we consider data from Ukraine. We also conduct historical data analysis. This allows you to assess the events that have already occurred, to understand what changes need to be made in the foreign exchange market.

\section{Related Works}

There are many works that use the theory of wavelets to analyze data describing the economic dynamics of various research objects.

For example, Aloui and Hkiri (2014), consider the short term and long term dependencies between stock market returns for the Gulf Cooperation Councils. For this analysis, the authors use the wavelet coherence methodology. This allows you to identify new dependencies and explain changes in the data that you can observe.

Uddin et al. (2013), based on the theory of wavelets, reveal the relationship between oil prices and exchange rates. At the same time, the use of the wavelet methodology allows one to determine the form of such a connection. The authors showed that that the strength of the relationship between oil price and exchange rate keeps changing.

Rua \& Nunes, (2009) investigate stock market returns. The paper shows that wavelet analysis allows one to assess the movement of resources in the stock market. Such an assessment is carried out in the time-frequency space. It allows one to provide a richer analysis of the comovement of various securities.

We can also see that Yang et al. (2016) use the wavelet coherence methodology to analyze the relationship in foreign exchange markets. The authors note that this approach allows us to study shorter time periods independently of longer time periods at all frequency bands of scale over the sample period.

In the work of Aloui et al. (2018), attention is paid to the assessment of the relationship between oil prices, inflation, exchange rate and economic growth in Saudi Arabia. The authors emphasize that this can be done using the wavelet coherence methodology. The authors also emphasize that this provides a fresh insight into the dynamic nexus between oil prices, the Saudi/US dollar exchange rate, inflation, and output growth rate in Saudi Arabia 'economy, using novel methods.

The authors of the study on the assessment of the dynamic relationship between exchange rates and stock prices in BRICS countries also use wavelet analysis methods (Dahir et al., 2018). The authors conclude that the use of wavelet analysis gives important results. The authors especially note that these results have important implications that investors should take into account in frequency-varying exchange rates and stock returns (Dahir et al., 2018).

Thus, we see that wavelet analysis gives good results when examining economic data. In this case, a special place among the methods of the theory of wavelets is given to the methodology of wavelet coherence.

\section{Wavelet Coherence as an Analysis Tool}

Wavelet coherence is one of the methods of wavelet theory that is used to analyze data in the form of a time series. Wavelet coherence allows cross-analysis of data. This contributes to a more detailed analysis of the data, allow you to reveal all the relationships between the data. At the same time, this can be done for different time intervals. 
Suppose we have two series of data $g(t)$ and $q(t)$ then we can determine the wavelet coherence (Torrence \& Webster, 1999; Vasiurenko \& Lyashenko, 2020):

$$
R^{2}(g, q)=\frac{\mid \Theta\left(q^{-1} W_{x y}(g, q) \mid\right.}{\Theta\left(q^{-1}\left|W_{x}(g, q)\right|^{2}\right) \Theta\left(q^{-1}\left|W_{y}(g, q)\right|^{2}\right)},
$$

where: $W_{x y}(g, q)$ - values of cross wavelet spectra ( $\mathrm{x}$ is the variable that displays the data number in the series under investigation and $\mathrm{y}$ is the variable that displays the depth of crosslinks for a time series); $\Theta-$ is a smoothing operator; $R^{2}(g, q)$ - The squared wavelet coherency coefficient. $0 \leq R^{2}(u, s) \leq 1$. If these values tend to zero, then we have a weak correlation. Otherwise, we have a strong correlation (Torrence \& Webster, 1999).

\section{Data for Analysis}

For analysis, we consider the data of the quotes of such currency pairs as: USD/UAH, EUR/UAH, RUB/UAH. These are the most common currency quotes in Ukraine. We are considering buy/sell the respective currency pairs. We are considering the time period 20142018. All data from official sources - https://minfin.com.ua/currency/mb/.

In Figure 1 shows the quote for the USD/UAH pair.

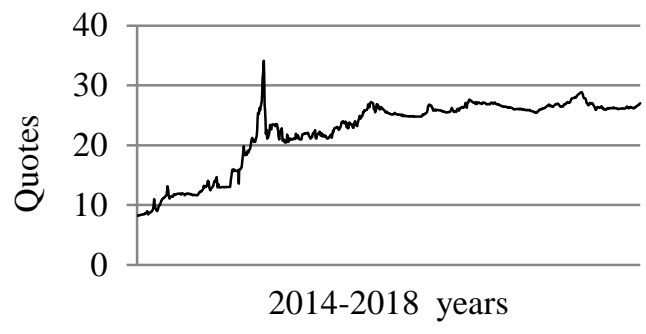

a) buy

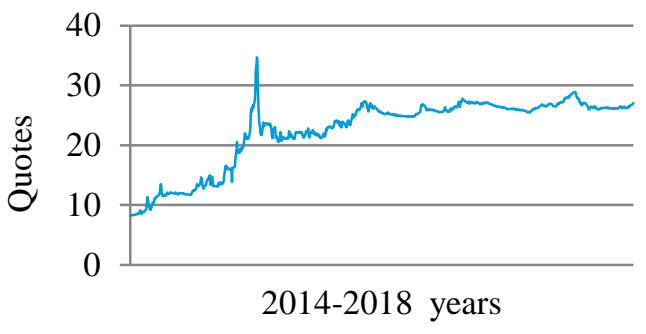

b) sell

Figure 1. The quote for the USD/UAH pair

In Figure 2 shows the quote for the EUR/UAH pair.

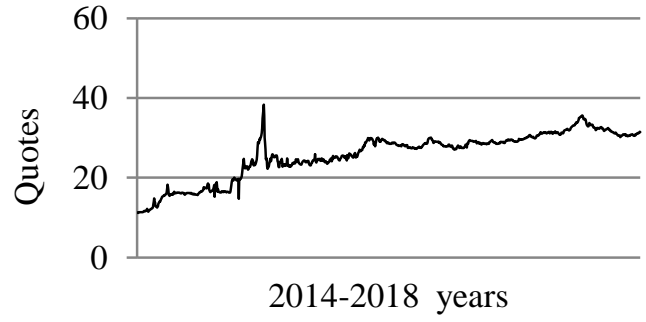

a) buy

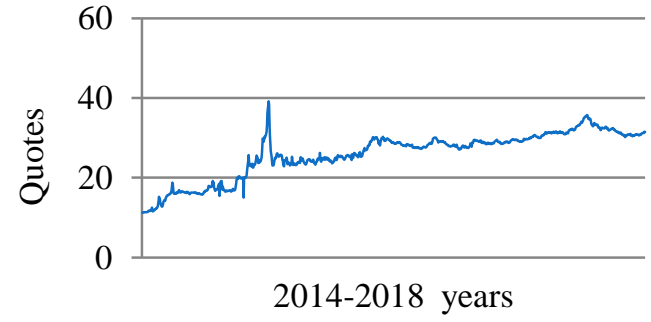

b) sell

Figure 2. The quote for the EUR/UAH pair 
In Figure 3 shows the quote for the RUB/UAH pair.

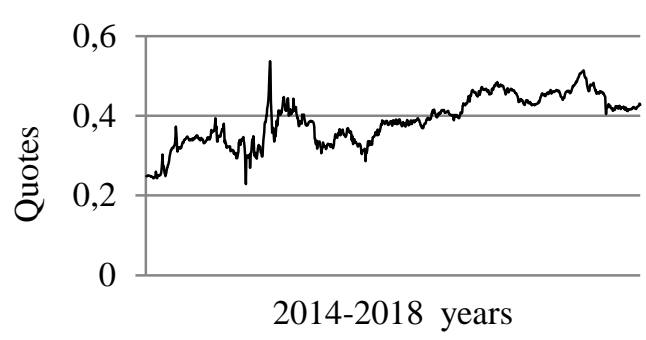

a) buy

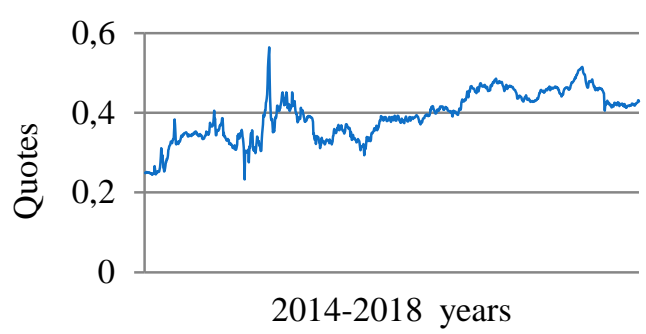

b) sell

Figure 3. The quote for the RUB/UAH pair

We see different dynamics of data. At the same time, such dynamics are characterized by a surge at the beginning of the period under study.

\section{Results and Discussion}

For further analysis, we use the wavelet coherence methodology (Torrence \& Webster, 1999; Vasiurenko \& Lyashenko, 2020). In Figure 4 shows the results of a wavelet analysis between buying and selling dynamics for different currency pairs (for 2014-2018 years).

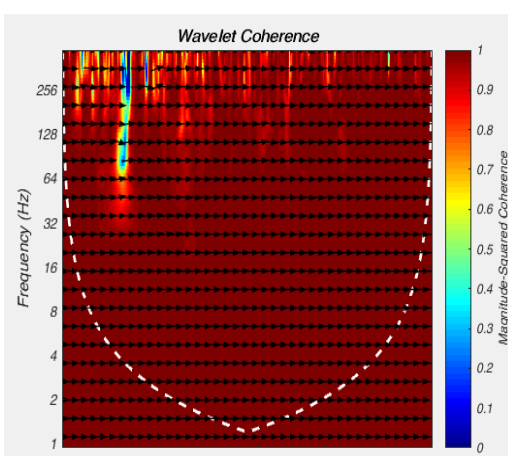

a) USD/UAH

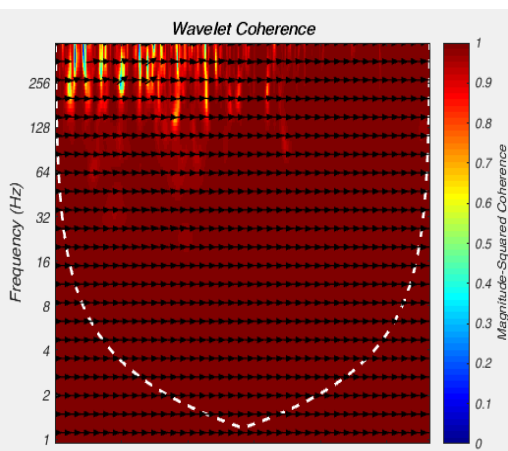

b) EUR/UAH

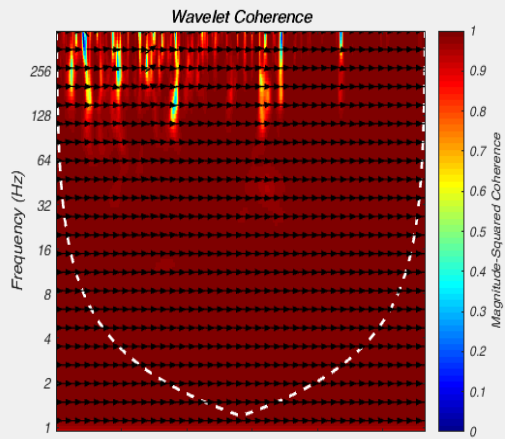

c) RUB/UAH

Figure 4. The results of a wavelet analysis between buying and selling dynamics for different currency pairs (for 2014-2018 years).

We see that the data in Figure 4 show different consistency between buying and selling dynamics for different currency pairs. This speaks of instability in the Ukrainian currency market. Such instability is typical for the initial periods of time from the interval being studied.

At the same time, this imbalance between buying and selling dynamics for different currency pairs decreases over time. Thus, the instability in the foreign exchange market in Ukraine is decreasing. Therefore, let's take a closer look at the data for 2014.

In Figure 5 shows the results of a wavelet analysis between buying and selling dynamics for different currency pairs (for 2014 data). 


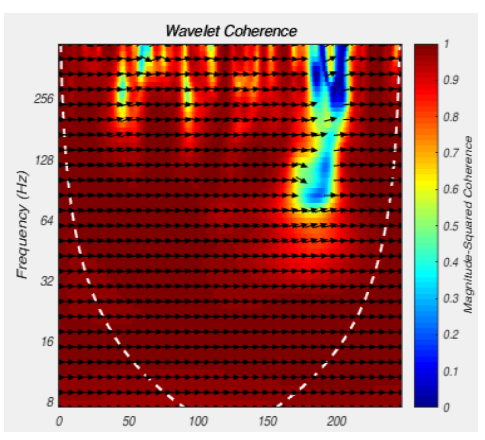

a) USD/UAH

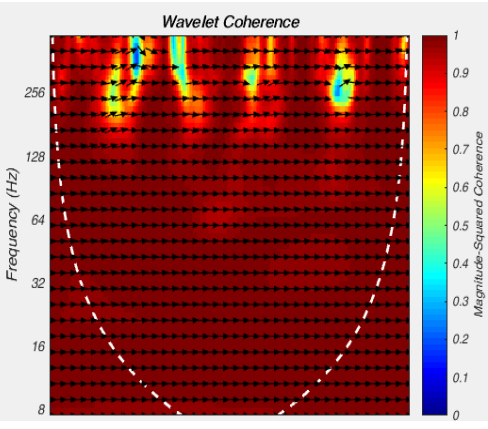

b) EUR/UAH

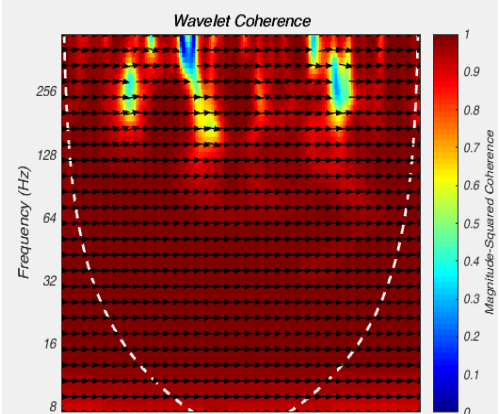

c) RUB/UAH

Figure 5. The results of a wavelet analysis between buying and selling dynamics for different currency pairs (for 2014 data).

We see that for different currency pairs, there are different scenarios of consistency between the dynamics of buying and selling currencies. The greatest inconsistency is typical for the USD/UAH pair. This is due to the largest volumes of transactions for this pair. It is also important to note that such inconsistency in the USD/UAH pair manifests itself in the form of a spike at the end of the period being studied. For the EUR/UAH and RUB/UAH currency pair, the inconsistency appears evenly throughout 2014.

The ambiguity in the foreign exchange market is also confirmed by the imbalance of the USD/EUR and USD/RUB currency pairs. In Figure 6 shows the wavelet coherence ratios for the USD/EUR pair. In Figure 7 shows the wavelet coherence ratios for the USD/RUB pair.

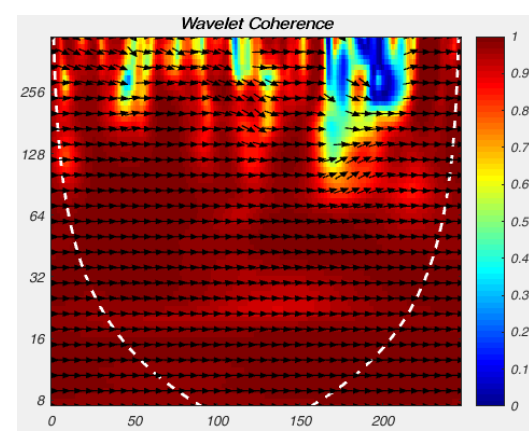

a) buy

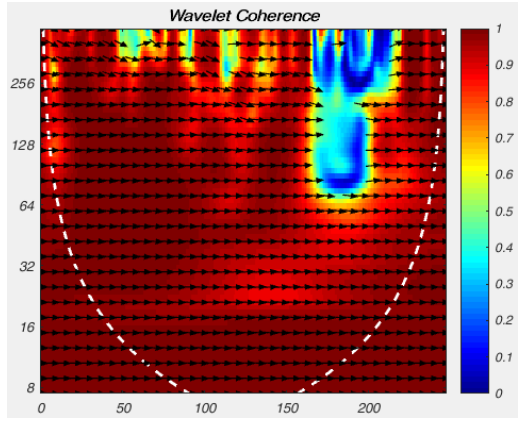

b) sell

Figure 6. The wavelet coherence ratios for the USD/EUR pair (for 2014 data).

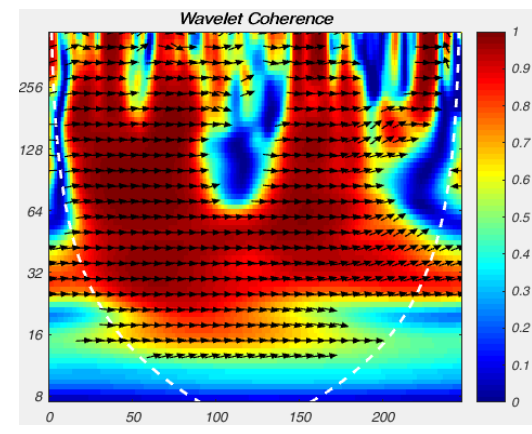

a) buy

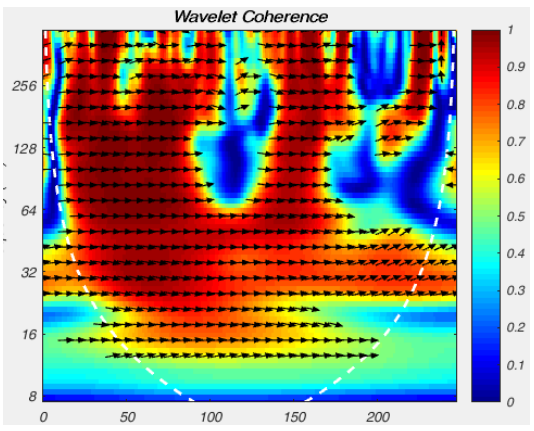

b) sell

Figure 7. The wavelet coherence ratios for the USD/RUB pair (for 2014 data).

We see that the greatest imbalance is in the USD / RUB pair. This fully coincides with the economic situation that developed in Ukraine in 2014.

Copyright $@$ C 2020, Journal of Asian Multicultural Research for Economy and Management Study, Under the license CC BY-SA 4.0 


\section{Conclusion}

We considered the possibility of applying the theory of wavelet analysis to the research of data on the foreign exchange market. As a method of the wavelet theory, we used the wavelet coherence methodology. For the analysis, we have selected data from the Ukrainian currency market. We have shown the feasibility of using the wavelet coherence methodology for studying the foreign exchange market. In particular, we showed the inconsistency of the foreign exchange market in Ukraine for certain time periods. This allows you to make informed decisions, pursue investment and foreign exchange policies, and choose the necessary strategies for the development of the foreign exchange market.

\section{References}

Aloui, C., \& Hkiri, B. (2014). Co-movements of GCC emerging stock markets: New evidence from wavelet coherence analysis. Economic Modelling, 36, 421-431.

Aloui, C., Hkiri, B., Hammoudeh, S., \& Shahbaz, M. (2018). A Multiple and Partial Wavelet Analysis of the Oil Price, Inflation, Exchange Rate, and Economic Growth Nexus in Saudi Arabia. Emerging Markets Finance and Trade, 54(4), 935-956.

Dahir, A. M., Mahat, F., Ab Razak, N. H., \& Bany-Ariffin, A. N. (2018). Revisiting the dynamic relationship between exchange rates and stock prices in BRICS countries: A wavelet analysis. Borsa Istanbul Review, 18(2), 101-113.

Dobrovolskaya, I., \& Lyashenko, V. (2013). Interrelations of banking sectors of European economies as reflected in separate indicators of the dynamics of their cash flows influencing the formation of the resource potential of banks. European Applied Sciences, 1-2, 114-118.

Kuzemin, A., Lyashenko, V., Bulavina, E., \& Torojev, A. (2005). Analysis of movement of financial flows of economical agents as the basis for designing the system of economical security (general conception). In Third international conference «Information research, applications, and education, 27-30.

Lyashenko, V. (2014). Efficiency of bank crediting of real sector of economy in the context of separate banking groups: an empirical example from Ukraine. International Journal of Accounting and Economics Studies, 2(2), 74-79.

Rua, A., \& Nunes, L. C. (2009). International comovement of stock market returns: A wavelet analysis. Journal of Empirical Finance, 16(4), 632-639.

Torrence, C., \& Webster, P. J. (1999). Interdecadal changes in the ENSO-monsoon system. Journal of climate, 12(8), 2679-2690.

Uddin, G. S., Tiwari, A. K., Arouri, M., \& Teulon, F. (2013). On the relationship between oil price and exchange rates: A wavelet analysis. Economic Modelling, 35, 502-507.

Vasiurenko, O., \& Lyashenko, V. (2020). Wavelet coherence as tool for retrospective analysis of bank activities. Ekon. Prognozuvannâ, 2, 43-60.

Yang, L., Cai, X. J., Zhang, H., \& Hamori, S. (2016). Interdependence of foreign exchange markets: A wavelet coherence analysis. Economic Modelling, 55, 6-14.

Copyright $@$ 2020, Journal of Asian Multicultural Research for Economy and Management Study,

Under the license CC BY-SA 4.0 